\title{
Null Sex Differences in General Intelligence: Evidence from the WAIS-III
}

\author{
Roberto Colom, Luis F. García, Manuel Juan-Espinosa, and Francisco J. Abad \\ Aulonomous University of Madrid
}

\begin{abstract}
There is an increasing number of studies claiming that the sex differences in genera] intelligence are "real." The empirical evidence is based on the summation of the standardized sex differences in several cognitive batteries. However, the scientific construct of general ability rests on the correlations among test scores, rather than on their summation. The latter (ability in gencral) is an arbitrary variable, not a scientific construct. General ability is not a function of any particular cognitive test, but a source of variance evidenced by the correlation between several diverse tests, each of which reflects general ability $(g)$ to some cxtent, but also group factors and test specificity. Because there are important educational, economic, and social consequences of a group difference in general ability, it is especially germane to evaluate the possibility of an average sex difference in its proxy measures, such as $1 Q$. The Spanish standardization of the WAISIII is analyzed in the present study. The sample was made up of 703 females and 666 males, aged 15-94. drawn as a representative sample of the population in temis of educationat level and geographical location. Although a male adwantage of 3.6 IQ points is observed, the difference is in "ability in general," not in "generai ability" $(\xi)$. Given that the main ingredient of the strong association between IQ and a broad range of social correlates is $g$, and given that there is no sex difference in $g$, then the average IQ sexdifference favoring males must be attributed to specific group factors and test specificity.
\end{abstract} Koy wond: general intelligence, sex differences, cognitive abilities, pkychological assessment, practical validity

\begin{abstract}
Un número creciente de estudios sostiene que "existen" diferencias entre los sexos en inteligencia general. Las pruebas empiricas se basan en la suma de las diferencias estandarizadas entre los sexos en diversas baterías cognitivas. Sin embargo, el constructo científico de inteligencia general se basa en la correlación entre las puntuaciones obtenidas en los tests, no en su suma. La suma de puntuaciones (inteligencia en general) constituye una variable arbitraria, no un constructo científico. La inteligencia general no es función de un determinado test, sino que constituye una fuente de varianza puesta de manifiesto por la correlación entre diversos tests, cada uno de los cuales refleja inteligencia general ( $g$ ), factores de grupo y especificidad del propio test. Puesto que existen importantes consecuencias educativas, económicas y sociales de las diferencias de grupo en inteligencia general, resulta especiaimente pertinente valorar la posibilidad de que exista una diferencia promedio entre sexos en medidas como el $\mathrm{Cl}$. En este estudio se emplea la adaptación española del WAIS-III. La muestra está formada por 703 mujeres y 666 varones de entre 15 y 94 años de edad, representativa de la población en nivel educativo y localización geográfica. Aunque se observa una ventaja promedio de los varones de 3.6 puntos de $\mathrm{Cl}$, la diferencia se debe a la "inteligencia en general", no a la "inteligencia general" (g). Dado que el principal ingrediente de la fuerte asociación que existe entre el $\mathrm{Cl}$ y un amplio conjunto de correlatos sociales es $g$. y que no existe una diferencia según el sexo en $g$, entonces la diferencia promedio de $\mathrm{Cl}$ que favorece a los varones debe atribuirse a los factores de grupo y a la especificidad de los tests.

Palabras clave: inteligencia general, diferencias de sexo, aptitudes cognitivas, evaluación psicológica, validez práctica
\end{abstract}

The fcsearch referred to in this article was supported by a grant funded by the Spanish Ministerio de Educación y Cultura. Grant Na PB98-0066. We are grateful to TEA. S.A. for providing the databnse analyzed in the present study, with special thanks to Dr. Nicolás Seisdedos. Correspondence concerninar this article should be addressed to Roberto Colom. Facultad de Psicología. Universiad Autónoma de Madrid. Ciudad Universilaria de Cantoblanco. 28049 Madrid (Spain). E-mail; roberto.colom@uam.es _ 
It is usually stated that sex differences in general inteilectual ability are nonexistem (Brody, 1992; Colom, 1998; Halpen. 1992: Jaan-Espinosa, 1997; Neisser el al.. 1996). 1 Howevel. Ankey (1992, 1995). Rushton (1992), and Lym (1994, ly9s. 1999) noted a paradox: Males, on the average have larger brains than females and brain size is positively associaled with intelligence (Jensen, 1998; Mackintosh. 1998; Rushton \& Ankcy, 1996). Hence, it would to expected that males would have a higher average fevel of intelligence than females.

In an extensive review, Lymn (1994) calculated a mean sex difference in general intelligence of $3.8 \mathrm{IQ}$ points lavoring males, precisely the advantage that can be predicted from males larger brains. This prediction is batsed on a mean correlation of 35 between in vivo brain size (neasured by OMRI, see Rushton \& Ankey, 1996) and IQ. and a sex differenee of 78 SD is adult brain size (autopsied brains). hence a predicted male-female difference in 19 ol $.35 \times .78$ $\mathrm{SD}=.27 \mathrm{SD} \times 15 \cong 4 \mathrm{IQ}$ points. Five years later. Lym (1909). p. 10) statcd that "males do have higher men 10 s than fomales by approximately $4 \mathrm{IQ}$ points, commensurate with ther larger averige brain size. This conclusion holds. whether general intelligence is detined as the sum of the verbal comprchension, reasoning, and spatial group factors, as fuid intelligence or reasoning ability, or as Spearman's $g$ measured from the first principal component ot as the global tQ obtained from standaud intelligence and aptitude tests. so long als this fublils the conditions stipulated by Jensen." Lynn (1999) considered 20 further data sets on sex diflerences that correspond with the 1994 estimates for general intelligence (Lynn. 1994).

The question of whether or not there is a sex difference in general intelligence is especially germane for psychological assessment. Thus, for instance, the practical validity of measures of general intelligence is usually indicated by a significant predictive useful correlation with some educational, conomic, or social criterion. Highly g-loaded test scores (KQ, see below) show a greater universal practical walidity than any other psychological construcl. IQ predicts performance in every kind of behwior that calls for learning, decision. and judgment. The vitidity of IQ is an increasing momotonic: lunction of the level of cognitive complexily in the critcrion. The statistical removal of $g$ from any psychometric test or battery, leaving only group lactors, produces a negligible practical validity when they are used in a representative population (Gordon, 1997; Gottfredson, 1986,1997a. 1997b).

The sencral factor $(g)$ than can be extrated from a correlation matrix hetween several cognitive tests predicts scholastic achicvement, because $g$ is intrinsic to learming novel material, grasping concepts, meanings, and so forth. Furthermore, $g$ is the man cognitive corrclate and best single predictor of success in job training and job performance. Metal-analyses of hundreds of test validation studies have shown that the validity of a highly g-loaded test with proven validity for a particular job in a particular organizational setting is generalizable to all other jobs and seltings (Ree \& Earles, 1991; Schmid, Hunter, Oterbridge, \& Goll, 1988).
'The s factor is still reflected in other broit social outcomes, as socjal problems sucl as dropping out of selow, chromic wellare status. child-neglect poverty, accident proneness, delinquency, or crime. These retitionships alre real independently of social class of origin. 'These social correlates have an inverse monotonic relation to 19 in the population. showing. ol average, live times the percentage of occurnence in the lowest quartile of the rotal distrityution of JQ at in the highest quartile (Hermstein \& Marray, 1944: Hunt, 1995; Mackintosh. 1998; Neisser et al., 1996).

The educational. economic. and social consequences of a group difference in IQ arise from two effects: (a) the statistical charatereristics of the nomal curve, and (b) the minimum probable threshold of the level of ability recpuired for cortain social altainments.

When lwo mormal distributions of IQ bave different mans. although the curves largely owerlap one another, a given cutolfpoint on the IQ scale can make a very large difference between the proportioms of the lower scoring group and the highes scoring group that fall below the cutoff-point. The further the distance of the cutolf-point from the mean of the higher scoring group, the larger will be the group difference hetween the proportion of each group that falls above or below the cutoff score (Jensen, 1980). Cutting seores on the 10 seile that fall at critical ifreshosds result in dispatrities between the proportions of the higher and lower scoring groups that latl into different social and occupational catcorones (Hunter. 1983. 1986; Hunter \& Hunter, 1984; Hunter \& Schmidt, 1990; McHenry, Hough, Tojuam, Hanson, \& Ashworth, 1990).

Consider a mean group difference of 3.810 points. Assume that adinission to a highly selective training course is based on a cutting $1 \mathrm{Q}$ scorc of 120 . What percentage of each group fulls above the culotf score? (See ligure 1.) For the group with a mean 10 of 100 , the corresponding $z$ score is 1.33 . The area of the normal curve lalling above $1.33 \%$ is $9.18 \%$. For the group with a mean IQ of 96.2 . an IQ of 120 is equivalent to at a score of 1.59 . The area of the nomnal curve falling above $1.59-$ is $5.50 \%$. Therefore an excess of approximately $3 \%$ of the bigher scoring group balis athove the culof score.

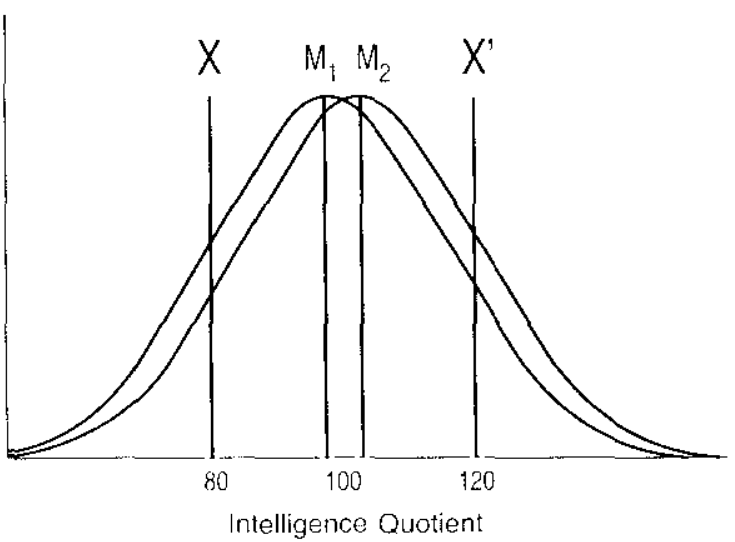

Figure /. Two nomal distributions: $\mathrm{M}_{2}=100$ and $\mathrm{M}_{2}=96$. The figure also represents two cutofl sores at $X^{\prime}(1 Q=80)$ and $X^{\prime}(1 Q=120)$. 
It should be noted that sudies of sex differences in generil ability have been confounded by improper defintions and measurements of general ability based on the simple stmmation of subtest scores from several batleries that differ in their group factors (for example, see reports by Lynn: Haltori \& Lynn, 1997; Lynn, 1994. 1998. 1999), The analyses yield a mean sex difference in the total score, but such results ate arbitrary, of limied generality, and of litte scientific (and practical) interest (Jensen. 1998). Some recent analyses have poincd out a negligible sex djfference in gencral intelligence defined as $g$ after a broad variety of cognitive and scholastic batteries Aluja, Colom, Abad, \& Juan-Espinosa, 2000; Colom, Juan-Espinosa. Abad, \& García, 2000; Jensen, 1998). Although the mean standardized sex difference was in strong agreement with the one reported by Lynn (1994, 1998, 1999: Hattori \& Lynn, 1997). the difference was not attributable to $g$. It must be emphisized that the simple sum of various subtest scores is of no scientific or practical interest, because it cannot be considered a proper measure of general ability. The concept of general ahility, detined as $g$, rests on the correlations among lest scores rather than on their summation. The latter (ability in general) is an arbitrary variable, not a scientilic construct.

The empirical fact that all mental abilities are positively corrclated calls for an analytic taxonomy of mental abilities based on some form of corrclation analysis. The dimensions found in the factor analysis of the correlations among a variety of mental ability measurements can be arranged hierarchically according to their generality (Carroll, 1993, 1997). The $g$ factor is the most general of all and is common to all mental abilitics. The $g$ fuctor is a common source of individual differences in all cognitive tests. The knowledge and skills tapped by test performance merely provide a vehicle for the measurement of $g$ (Jcnsen, 1992). Not cvery vehicle is a fine measure of the construct. The construct must be elicited in many different ways. It is not a function of any particular vehicle, but a source of variance evidenced by the correlation between sevetal diverse tests. each of which reflects $g$ to some extent, but may also reflect group factors and test specificity.

No pure test of $g$ exists. The solution is to obtain a composite score from several highly diverse g-loaded tests. The greater the numbers of tess that enter into the composite score, the more the unwanted sources of variance are averaged out. In the best-standirdized test batteries, $75 \%$ of more of the vartince of the composite scores consists of g. This is typical for most individual to wests (such as the Wechsler). Each test score reflects the level of $g$ and the properties of the test itsclf (Catlell, 1978; Jensen, 1998).

In short, a key question in the research on cognitive sex differences is whether, on average. females and males dilfer in $g$. This question is technically the nost difficult to answer and hats heen the loas investigated. This article examines sex differences in terms of the gractor extuated from the Spanish standardization of the WAIS-III. We investigated whether there is any sex ditterence in gencral inteiligence chefined as $g$.
Method

\section{Participants and Measures}

The Wechsler Adult Intelligence Scale (WAIS-III: Wechsicr, 1997) was standiadized in Spain in 1998. The standardization sample consisted of 703 females and 666 men, aged 15-94 $\left(N_{16-10)}\right.$ years $=163: N_{20-24 \text { ytars }}=153: N_{25}$ .44 years $=272: N_{35-54 \text { yeirs }}=408 ; N_{55-69 \text { ycars }}=237 ; N_{70 \mathrm{or}}$ Itwre ycars $=136)$, drawn ats a representative sample of the population in forms of educational level (academic level zero $=300 ;$ academic level one $=429$; actdemic level $\mathrm{two}=524$; and academic level thee $=111$ ) and geographical location $\left(N_{\text {North }}=348, N_{\text {Center }}=299, N_{\text {East }}=359, N_{\text {Sinuth }}=363\right)$.

The Spanish slandardization of the WAIS-III includes 14 well-known subtests: vocabulary. similarities, arithmetic. digit span, information, comprehension. letter-number series. picture completion, coding, block design, matrices, picture arangement, symbol seatch, and object assembly.

\section{Andyes}

The method of correlated vectors is especially appropriate for comparing tho vectors defined by the $g$ loadings of a varicty of tests and the standardized mean group differences (d) in those lests (Colom et al.: 2000, Jensen, 1998). This method must comply with severat conditions (see Jensen for more detajls): The samples must be large and representative, the number of tests analyzed must be large enough. the tests must be diverse, the tests' reliability coefficients must be taken into account, and the values corresponding to the congrucnce coefficicnts among the factors of interest obtained from the groups compared should be higher than 90 . The congruence coefficient $\left(\mathbf{r}_{\mathbf{c}}\right)$ is an index of factor similarity. If the groups show identity of the $g$ factor, combining the two vectors can increase the reliability of the vector of $g$-loadings (Jensen, $[998$ ).

The statistical lest of the hypothesis concening mean group differences is the correlation between the vector of the tests" g loadings and the vector of standandized mean differences between the groups on each of the tests $(d)$. akiug the rests' reliability coetticients into account. The method for tasting the bypothesis depends on the magnitudes of the group difference across tests that differ in their $g$ loadings. The Spearman rank-order correlation $\left(r_{s}\right)$ of the column vector of subests $g$ loadings with the vector of the sex differences $(d)$ on the subtests indicates the degree 10 which $g$ is relatcd to the rank order of the sex differences on the various subtests. If the correlation is not statistically significant, then the standardized sex differences $(d)$ are not related to general intelligence defined as $s$.

We performed a hierarchical factor analysis (SchmidLeiman transtormation) separately for males and females. In the Schmid-Leiman transformation (Schuid \& Leiman, 1957), the higher order fictors are allowed to account for as much 
Table l

Descriptive Data and Standardized Mean Differences (d)

\begin{tabular}{|c|c|c|c|c|c|c|c|}
\hline \multirow{2}{*}{ WAIS-III subtests } & \multicolumn{3}{|c|}{ Males } & \multicolumn{3}{|c|}{ Females } & \multirow[b]{2}{*}{$d$} \\
\hline & $M$ & $S D$ & $N$ & $M$ & $S D$ & $N$ & \\
\hline 1. Vocabulary & 38.12 & 13.44 & 665 & 36.28 & 14.00 & 702 & .13 \\
\hline 2. Similarities & 17.40 & 6.93 & 666 & 16.65 & 6.62 & 703 & .11 \\
\hline 3. Arithmetic & 13.37 & 3.92 & 666 & 11.19 & 3.62 & 702 & .58 \\
\hline 4. Digit Span & 15.46 & 4.75 & 666 & 14.16 & 4.44 & 703 & .28 \\
\hline 5. Information & 17.32 & 5.88 & 666 & 14.85 & 5.99 & 703 & .42 \\
\hline 6. Comprehension & 18.54 & 6.17 & 666 & $\$ 7.56$ & 6.11 & 703 & .16 \\
\hline 7. Letter-Number & 9.88 & 3.58 & 665 & 9.01 & 3.51 & 702 & .25 \\
\hline 8. Picture Completion & 18.12 & 5.17 & 665 & 17.48 & 5.35 & 702 & .12 \\
\hline 9. Coding & 64,58 & 24.94 & 661 & 60.26 & 27.11 & 702 & .17 \\
\hline 10. Block Design & 40.17 & 14.68 & 662 & 35.23 & 14.47 & 701 & .34 \\
\hline 11. Matrices & 16.33 & 6.28 & 666 & 14.61 & 6.40 & 703 & .27 \\
\hline 12. Picture Arrangement & 12.93 & 5.89 & 665 & 11.80 & 5.81 & 701 & .19 \\
\hline 13. Symbol Search & 29.75 & 11.86 & 661 & 27.44 & 12.06 & 702 & .19 \\
\hline 14. Object Assembly & 30.48 & 10.64 & 664 & 28.82 & 10.42 & 702 & .16 \\
\hline
\end{tabular}

Note. The $d$ values were computed by dividing the mean difference between the groups by their pooled within-group standard deviation.

of the comelation among the observed variables as possible, whereas the lower order factors are reduced to residual factors uncorrelated cither to each other or to the higher order factors. Therefore, each factor represents the independent contribution of the factor in question (Carrol:, 1993; Loehlin, 1992).

Besides the method of correlated vectors, still another method for examining the sex difference in psychometric $g$ is to represent the sex difference on each of the subtests in terms of a point-biserial correlation among subtests' scores and the sex variable, and include these correlations within the full matrix of subtest intercorrelations for factor analysis.
The result will reveal the factor loading of sex on each of the factors that cmerges from the analysis, including $g$. The factor loading of sex is equivalent to the point-biserial correlation between $g$ and the sex variable.

\section{Results}

The descriptive data are shown in Table 1. The standardized sex differences $(d)$ used for subsequent study of the relationships with the $g$ loadings are also shown.

Table 2

Correlation Matrix of the WAIS-II Subtests (Male Correlations at the Top Half. Fenale Correlations at the Bottom Half). Reliabilities along the Diagonal

\begin{tabular}{|c|c|c|c|c|c|c|c|c|c|c|c|c|c|c|}
\hline Subtests & 1 & 2 & 3 & 4 & 5 & 6 & 7 & 8 & 9 & 10 & 11 & 12 & 13 & 14 \\
\hline 1. Vocabulary & .95 & .747 & .643 & .536 & .710 & .741 & .611 & .613 & .582 & .607 & .653 & .608 & .586 & .547 \\
\hline 2. Similarities & .768 & .89 & .619 & .541 & .670 & .701 & .599 & .633 & .555 & .604 & .654 & .635 & .565 & .557 \\
\hline 3. Arithmetic & .601 & .604 & .88 & .582 & .668 & .580 & .665 & .607 & .579 & .635 & .703 & .584 & .608 & .583 \\
\hline 4. Digit Span & .581 & .596 & .637 & .89 & .505 & .486 & .753 & .506 & .582 & .526 & .569 & .565 & .584 & .568 \\
\hline 5. Information & .731 & .704 & .632 & .567 & .93 & .653 & .579 & .593 & .503 & .615 & .634 & .596 & .511 & .525 \\
\hline 6. Comprehension & .719 & .703 & .546 & .520 & .698 & .85 & .565 & .553 & .507 & .498 & .572 & .583 & .497 & .507 \\
\hline 7. Letter-Number & .643 & .624 & .680 & .764 & .619 & .573 & 91 & .582 & .669 & .624 & .661 & .669 & .663 & .601 \\
\hline 8. Picture completion & .624 & .617 & .558 & .579 & .615 & .562 & .653 & .91 & .624 & .683 & .728 & .687 & .636 & .636 \\
\hline 9. Coding & .622 & .604 & .581 & .592 & .552 & .496 & .705 & .659 & .82 & .648 & .657 & .680 & .761 & .631 \\
\hline 10. Block design & .595 & .611 & .596 & .594 & .597 & .496 & .681 & .686 & .684 & .94 & .755 & .713 & .678 & .746 \\
\hline 11. Matrices & .667 & .692 & .692 & .640 & .627 & .563 & .711 & .700 & .750 & .776 & .94 & .757 & .727 & .691 \\
\hline 12. Picture arrangement & .626 & .622 & .600 & .574 & .639 & .573 & .663 & .674 & .659 & .671 & .754 & .86 & .672 & .696 \\
\hline 13. Symbol search & .592 & .576 & .565 & .536 & .548 & .490 & .683 & .617 & .807 & .668 & .708 & .666 & .77 & .676 \\
\hline 14. Object assembly & .580 & .565 & .505 & .535 & .556 & .489 & .593 & .616 & .618 & .74 .3 & .697 & .660 & .625 & .68 \\
\hline
\end{tabular}


Table 3

Male and Fenale g Factor Loadings Extracted after a Hierarchical Factor Analysis (Schmid-Leiman Transformation); Average g Loadings are also Presented

\begin{tabular}{lccc}
\hline WAIS-III subtests & & $g$ loadings & Average $g$ loadings \\
\cline { 2 - 4 } & Males & Females & .77 \\
\hline 1. Vocabulary & .77 & .77 & .76 \\
2. Similarities & .76 & .76 & .76 \\
3. Arithmetic & .76 & .75 & .76 \\
4. Digit Span & .74 & .78 & .74 \\
5. Information & .73 & .75 & .70 \\
6. Comprehension & .71 & .69 & .84 \\
7. Letter-Number & .83 & .86 & .74 \\
8. Picture completion & .74 & .75 & .77 \\
9. Coding & .77 & .78 & .76 \\
10. Block design & .76 & .76 & .82 \\
11. Matrices & .81 & .83 & .78 \\
12. Picture arrangement & .79 & .76 & .76 \\
13. Symbol search & .77 & .75 & .71 \\
14. Object assembly & .73 & .69 & \\
\% Variance & 57.86 & 58.5 & \\
\hline
\end{tabular}

Table 2 presents the correlation matrix, separately for males and females. Subtests reliabilities are also included.

A Schmid-Leiman hierarchical factor analysis was computed separately for females and males. The $g$ factor was represented by the higher order factor. Table 3 shows the $g$ loadings for males and females. The congruence coefficient computed from the $g$ factor loadings in Table 3 for males and females was .999 . Hence, the $g$ factor is the same, irrespective of sex, so the average $g$ loadings can be computed to apply the method of correlated vectors.

The Spearman rank-order correlation between the vector of $g$ loadings and the vector of the standardized sex differences (d) was $r_{s}=.059(p=.840)$, a value suggesting a null sex difference in $g$ (Pearson $r=-.008, p=.979$, partial correlation controlling for $r_{x x}=-.0981, p=.750$ ). Figure 2 shows the scatter diagram corresponding to the correlation between the $g$ and $d$ vectors. This results in the failure to reject the null hypothesis of no sex differences in general intelligence defined as $g$.

The point-biserial correlations between sex and the WAIS-III subtests were also computed. These correlations were included within the full matrix of subtests correlations for factor analysis. The resulting $g$ loading of sex was .159 .

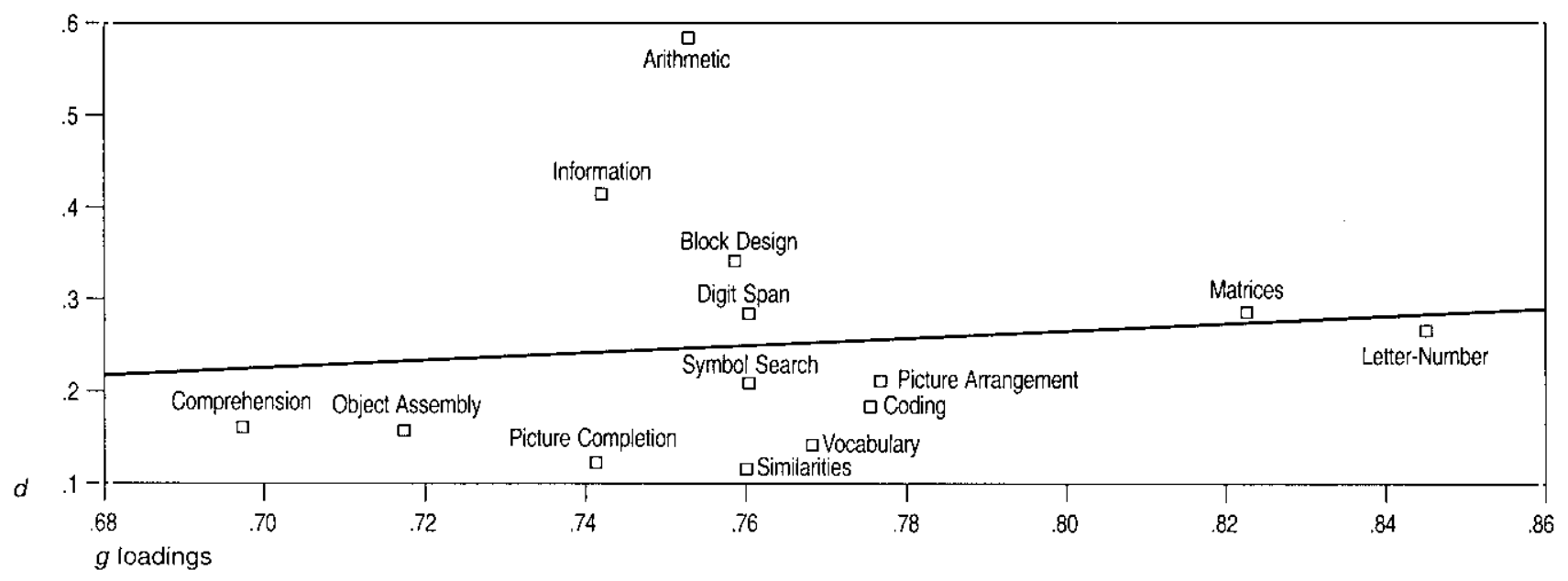

Figure 2. A scatter diagram of the correlation of the standardized sex differences $(d)$ with the WAIS-III subtests plotted as a function of the subcests' $g$ loadings. Spearman $\mathrm{r}=.059, p=.840$; Pearson $r=-.008, p=.979$; Partial correlation controljing for subtests' reliabilities $=-.0981 . p=.750$. 


\section{Discussion}

Jensen (1998) applied the method of correlated vectors for the comparison of the $g$-loadings in several cognitive batteries (WISC-R, WAIS, GATB, ASVAB, and the British Ability Scales, BAS) with the standardized sex difference (d) on the scales included in those batcries. The correlations found by Jensen (1998, p. 539) were $.346 .-.036, .024, .127$, and .103 , respectively. He also computed the $g$ loading of sex in those cognitive batteries, obtaining the values .094, $.006,-255, .180$, and -.001 , respectively. Jensen's (p. 540) main conclusion was: "The method of correlated vectors shows that in to case is there a correlation between subtests" $g$-loadings and the mean sex differences on the various subtests $[\ldots]$ the $y$-loadings of the sex differences are all quite small."

Colom et al. (2000) found a negligible sex difference in $g$ after the largest sample on which a sex difference in $g$ had ever been tested $(N=10,475)$. The Pearson $r$ of the column vector of subtests' $g$ loadings with the vector of the sex differences $(d)$ on the subtests was $122(p=.721)$. With the vector of reliability coefficients partialled out, the $g$ and $d$ vectors were correlated .051 . The Spearman rank order correlation was $.000(p=.999)$. Furthermore, the $g$ loading of sex was .216. Therefore, their findings are entirely consistent with those using quite different batteries and subject samples.

Aluja et al. (2000) found an average $g$-loading of sex of -.172 , using two samples of 670 and 887 young adolescents. Thus, the value was consistent with previous findings.

Considering all the available empirical evidence, including that we report in the present study after the Spanish standardization sample of the WAIS-III, the average correlation between $g$ and $d$ is .09 , whereas the average $g$ loading of the sex variable is .02 . Therefore, it is clear that the standardized sex difference in typical IQ tests cannol be attributed to general intelligence defined as $g$ (Aluja ct al., 2000, Colom et al., 2000, Jensen, 1998).

It is extremely important to gather cumulative evidence from different batteries and subject samples because, as Carroll $(1997$, p. 31$)$ has stated, " $g[\ldots]$ is likely to be present, in some degree, in nearly all measures of cognitive ability. Furthermore, it is an important factor, because on the average, over many studies of cognitive ability tests, it is found to constitute more than ball of the total common factor variance in a test."

New pieces of evidence must be considered, because there is an increasing number of studies claiming that the sex difference in general intelligence is "real" (Ankey, 1992, 1995; Lynn, 1994, 1998, 1999: Rushton, 1992). The present study shows that the supposed sex difference is a difference in "intelligence in general," but not in "general intelligence" (Aluja et al., 2000; Colom et al., 2000; Jensen, 1998).

The mean $d$ that can be calculated from the Table 1 of the present study is 0.241 . This value translates into 3.6
IQ points favoring males, not so far from the 3.8 IQ points reported by Lynn $(1994,1999)$. The important issue is that the method of correlated vectors contridicts the conclusion that could be derived from the simple summation of the standardized mean group differences $(d)$. Because of the greater scientific adequacy of the method of correlated vectors to test the null hypothesis concerning sex differences in general intelligence defined as $g$, we can conclude that there is no sex difference in general intelligence.

The null sex difference in $g$ suggests that: (a) The factor (g) that is present in nearly all measures of cognitive ability (and that accounts for more than half of the total common factor variance in a test) docs not differ between sexes; (b) non- $g$ factors and/or test specificity are responsible for the observed cognitive sex differences; and (c) the "paradox"-the findings of larger male brain, the association of brain size with IQ, and the absence of a sex difference in overall IQ-is not relevant to the problem of whether or not is there a sex difference in general intelligence, because there is no sex difference in general intelligence.

The practical importance of the null sex difference in $g$ is directly related to its social correlates. A difference betwcen the means of two population groups has a quite different kind of consequence than does the very same size difference when obtained between two individuals on the same scale. For groups, the most important consequence of a group difference in means is of a statistical nature. The consequences of population differences in $\mathrm{IQ}$ are of greater importance than are most other measurable characteristics that show comparable population differences (considering all the imponant social correlates of $1 Q$ ). Beciuse the percentage of individuals who fall in a given $S D$ range decreases so rapidly as one moves away from the mean and toward either tail of the normal distribution. it becomes obvious that the populations are disproportionately represented in the upper and lower tails (Figure 1). To the extent that there are different selection thresholds for the level of IQ required for certain levels of educational attainment, or for admission into colleges, occupations. or specialized training programs, population groups that differ in mean IQ will be represented unequally in the selection outcome. This is a direct consequence of the correlation botween $I Q$ and these socially significant variables within each population.

Given that the main ingredient of the association between IQ and these social correlates is $g$, and given that there is no sex difference in $g$, it must be concluded that the average IQ sex difference is attributable (by default) to group factors and/or to test specificity. Therefore. the functional difference between the sexes in the real settings where $g$ is functioning must be cxpected to be negligible. This evidence must be considered in the practical assessment of intelligence. 


\section{References}

Aluja, A., Colom, R., Abad, F.J., \& Juan-Espinosa, M. (2000). Sex differences in general intelligence defined as $g$ among young adolescents. Personality and Indinidual Differences, 28, 813-820.

Ankey, C. (1992). Sex differences in relative brain size: The mismeasure of woman, too? Intelligence, $16,329-336$.

Ankey, C. (1995). Sex differences in brain size and mental abilities: Comments on R. Lynn and D. Kimura. Personality and Individual Differences, 18, 423-424.

Brody, N. (1992). Intelligence (2nd ed.), San Diego, CA: Academic Press.

Carroll, J.B. (1993). Hunan cognitive abilities. A survey of factor analytic studies. Cambridge, MA: Cambridge University Press.

Carroll, J.B. (1997). Psychometrics, intelligence, and public perception. Intelligence, 24, 25-52.

Cattell, R.B. (1978). The scientific use of factor analysis. New York: Plenum.

Colom, R. (1998). Psicología de las diferencias individuales, Teoría y práctica. Madrid: Pirámide.

Colom, R., Juan-Espinosa, M., Abad, F.J. \& García, L.F. (2000). Negligible sex differences in general intelligence. Intelligence, 28, 57-68.

Gordon, R.A. (1997). Everyday life as an intelligence test: Effects of intelligence and intelligence context. Intelligence, 24, 203320.

Gottfredson, L. (Ed.) (1986). The $g$ factor in employment [Special Issue]. Joumal of Vocational Behavior, 29 (3).

Gottfredson, L. (1997a). Why $g$ matters: The complexity of everyday Iife. Intelligence, 24, 79-132.

Gottfredson, L. (1997b). Foreword to "Intelligence and Social Policy." Intelligence, 24, 1-12.

Halpern, D. (1992). Sex differences in cognitive abilities. Hillsdale, NJ: Erlbaum.

Hattori, K., \& Lynn, R. (1997). Male-female differences on the Japanese WAIS-R. Personality and Individual Differences, 23, $531-533$.

Herrnstein, R., \& Murray, Ch. (1994). The bell curve. Intelligence and class structure in American life. New York: Free Press.

Hunt, E. (1995). Will be we smart enough? A cognitive analysis of the coming workforce. New York: Russell Sage Foundation.

Hunter, J.E. (1983). Overview of validity generalization for the U.S. Employment Service (USES Test Research Report N 43). Washington, DC: U.S. Department of Labor, Employment and Training Administration.

Hunter, J.E. (1986). Cognitjve ability, cognitive aptitudes, job knowledge, and job performance. Journal of Vocational Behavior, 29, 340-362.

Hunter, J.E., \& Hunter, R.F. (1984). Validity and utility of altemative predictors of job performance. Psychological Bulletin, 96, 72 98.
Hunter, J., \& Schmidt, F. (1990). Methods of meta-analysis: Correcting error and bias in research finding. Newbury Park, CA: Sage.

Jensen, A. (1980). Bias in mental testing. London: Methuen.

Jensen, A. (1992). Vehicles of g. Psychological Science, 3, 275-277.

Jensen, A. (1998). The g factor. London: Praeger.

Juan-Espinosa, M. (1997). Geografía de la inteligencia humana. Madrid: Pirámide.

Loehlin, J.C. (1992). Latent variable models: An introduction to factor, path, and structural analysis ( $2^{\text {nd }}$ ed.). Hillsdale. NJ: Erlbaum.

Lynn, R. (1994). Sex differences in intelligence and brain size: A paradox resolved. Personality and Individual Differences, 17 , 257-271.

Lynn, R. (1998). Sex differences in intelligence: Data from a Scottish standardization of the WAIS-R. Personality and Individual Differences, 24, 289-290.

Lynn, R. (1999). Sex differences in intelligence and brain size: A developmental theory. Intelligence, 27, 1-12.

Mackintosh, N.J. (1998). IQ and human intelligence. Oxford, UK; Oxford University Press.

McHenry, J.J., Hough, L.M., Toquam, J.L., Hanson, M.A., \& Ashworth, S. (1990). Project A validity results; The relationship between predictor and criterion domains. Personnel Psychology, 43, 335-354,

Neisser, U., Boodoo, G., Bouchard, T., Boykin, A., Brody, N., Ceci, S., Halpern, D., Loehlin, J., Perloff, R., Sternberg, R., \& Urbina, S. (1996). Intelligence: Knowns and unkowns. American Psychologist, 51, 77-101.

Ree, M.J., \& Earles, J.A. (1991). Predicting training success: Not much more than $g$. Personnel Psychology, 44, 321-332.

Rushton, J.P. (1992). Cranial capacity related to sex, rank, and race in a stratified sample of 6,325 U.S. military personnel. Intelligence, 16, 401-414.

Rushton, J.P. \& Ankey, C.D. (1996). Brain size and cognitive ability: Correlations with age, sex, social class, and race. Psychonomic Bulletin and Review, 3, 21-36.

Schmidt, F.L., Hunter, J.E., Outerbridge, A.N., \& Goff, S. (1988). Joint relation of experience and ability with job performance: Test of three hypotheses. Joumal of Applied Psychology, 73, 46-57.

Schmid, J., \& Leiman, J.M. (1957). The development of hierarchical factor solutions. Psychometrika, 22, 53-61.

Wechsler, D. (1997). Wechsler Adult Intelligence Scale ( $3^{\text {rd }}$ ed.). San Antonio. TX: The Psychological Corporation. (Spanish adaptation: WAIS-III: Escala Wechsler para adultos. Madrid: TEA, 1998).

Received September 8, 2000 Revision received January 1, 2001 Accepted February 2, 2001 